\title{
Welding, longitudinal lung function decline and chronic respiratory symptoms: a systematic review of cohort studies
}

\author{
Joanna Szram ${ }^{1,2}$, Susie J. Schofield ${ }^{1,2}$, Martin P. Cosgrove ${ }^{3}$ and Paul Cullinan ${ }^{1,2}$
}

\section{Affiliations:}

'Dept of Occupational and Environmental Medicine, Imperial College (National Heart and Lung Institute), London,

${ }^{2}$ Royal Brompton and Harefield NHS Foundation Trust, London, and

${ }^{3}$ TWI (formerly The Welding Institute), Cambridge, UK.

\section{Correspondence:}

J. Szram, Dept of Occupational and Environmental Medicine, Imperial College (National Heart and Lung Institute), Emmanuel Kaye Building, 1b Manresa Road, London SW3 6LR, UK.

E-mail: joanna.szramaimperial.ac.uk

ABSTRACT While the acute respiratory risks of welding are well characterised, more chronic effects, including those on lung function, are less clear. We carried out a systematic review of published longitudinal studies of lung function decline in welders.

Original cohort studies documenting two or more sequential measurements of lung function were reviewed. Meta-analysis was carried out on studies with suitable data on forced expiratory volume in $1 \mathrm{~s}$ (FEV1).

Seven studies were included; their quality (measured on the Newcastle-Ottawa scale) was good, although exposure assessment was limited and the studies showed significant heterogeneity. Five had data suitable for meta-analysis; the pooled estimate of the difference in FEV1 decline between welders and nonwelders was $-9.0 \mathrm{~mL} \cdot$ year $^{-1}(95 \%$ CI $-22.5-4.5 ; \mathrm{p}=0.193)$. The pooled estimates of difference in annual FEV1 decline between welders and referents who smoked was $-13.7 \mathrm{~mL} \cdot$ year $^{-1}(95 \% \mathrm{CI}-33.6-6.3 ; \mathrm{p}=0.179)$. For welders and referents who did not smoke the estimated difference was $-3.8 \mathrm{~mL} \cdot$ year $^{-1}$ (95\% CI -20.2-12.6; $\mathrm{p}=0.650$ ). Symptom prevalence data were mainly narrative; smoking appeared to have the greatest effect on symptom evolution.

Collectively, available longitudinal data on decline of lung function in welders and respiratory symptoms suggest a greater effect in those who smoke, supporting a focus on smoking cessation as well as control of fume exposure in this trade. Further prospective studies are required to confirm these findings.

@ERSpublications

Welders who smoke suffer greater decline in lung function http://ow.ly/nUBBb

This article has supplementary material available from www.erj.ersjournals.com

Received: Nov 242011 | Accepted after revision: Dec 042012 | First published online: Dec 202012

Conflict of interest: None declared.

Copyright @ERS 2013 


\section{Introduction}

While there are no validated data, extrapolation from US estimates [1] suggests that worldwide there are several million full-time, occupational welders. Their numbers are likely to rise and, increasingly, they will be working in economies with uncertain workplace safety standards. While the acute health risks of welding are well characterised, more chronic adverse effects, including those on lung function, are less clear.

Reported adverse respiratory outcomes include metal fume fever [2], siderosis [3], lobar pneumonia [4] and less definitively, lung cancer [5,6] and asthma [7-12]. Although some studies have shown an increased prevalence of chronic bronchitis in welders [9], this finding is not universal [13]. Cross-sectional studies of lung function have also provided mixed results, with some [14-16], but not others [13, 17-19], reporting worse lung function than in referents. Issues limiting interpretation of cross-sectional data include the healthy-worker effect [9] and difficulties in establishing cause and effect and in eliminating the role of confounding exposures. Studies that follow cohorts of welders and unexposed referents should provide a more valid assessment of any risk of accelerated lung function decline attributable to exposure to welding fumes than cross-sectional studies.

We carried out a systematic review of published studies of longitudinal decline in lung function in welders and, in these, of any change in respiratory symptoms. Our aim was to understand how comprehensive and how consistent the available information was and to establish whether further research is warranted.

\section{Methods}

We are not aware of any prior systematic review of this kind. Using a series of search terms (online supplementary appendix 1) we interrogated seven databases to June 2011. From 203 identified papers, we selected eight studies which fulfilled our inclusion criteria (online supplementary appendix 1); we excluded a further study, designed specifically to measure the incidence of occupational asthma [7]. Given the lack of validated criteria for the quality assessment of observational studies, we constructed our own (online supplementary appendix 2) using relevant domains from the Newcastle-Ottawa Quality Assessment Scale [20].

We examined various factors that may influence lung function decline or the evolution of chronic respiratory symptoms: country and industry of study; metals and welding processes used; exposure assessment, such as duration of exposure or particulate measurement; age of cohort; length of follow-up; follow-up rate; and smoking status. We examined all published measurements of lung function and respiratory symptoms (dyspnoea, cough, sputum, chronic bronchitis and wheeze) as well as any supportive narrative information. Our methodology and reporting follow guidance on the Meta-analysis Of Observational Studies (MOOSE) [21]; more detail is provided in the online supplementary appendix 1.

Analyses using the "metan" command in STATA version 9 (StataCorp LP, College Station, TX, USA) were focused on measurements of annual decline in forced expiratory volume in $1 \mathrm{~s}$ (FEV1). Only those studies for which we had a variability statistic were used in meta-analysis; direct enquiries to the authors of some selected papers provided additional relevant information [22-24]. Statistical heterogeneity was assessed with the $\mathrm{I}^{2}$ test statistic; significant heterogeneity was indicated using a cut-off point of $\mathrm{p}<0.10$ [25] and fixed and random effects estimates were then compared. Annual decline of lung function comparing welders and controls in each study were then combined using random effects models to calculate a pooled weighted mean difference (WMD) with 95\% confidence intervals.

Pooled estimates were generated for smokers and nonsmokers separately. Forced vital capacity (FVC) was investigated as a secondary outcome. Funnel plots and further subgroup analyses to examine the sources of publication bias and heterogeneity were not attempted, due to the small number of studies and the lack of relevant, published information.

\section{Results}

Narrative summary of selected studies and lung function decline

All seven selected studies had a quality score $\geqslant 5$ (online supplementary appendix 1 ). They included between 24 and 269 welders with a median follow-up of 5 years (range 2-18 years). The annual FEV1 decline in welders ranged from -0.05 to $-47 \mathrm{~mL} \cdot$ year $^{-1}$ (table 1 ).

The earliest study, of welders in a vehicle manufacturer in France, suggested that FEV1 among welders who did not smoke and referents improved over 5 years of observation, with no decline seen in welders who smoked [26]. Two subsequent papers from the UK examined populations of welders/caulker-burners, caulker-burners alone and referents ("other trades"); in the first paper the authors concluded that welding fume exposure significantly increased lung function decline, independent of and additive to smoking [22]; in the second, smoking and welding each had a (smaller) effect on decline, with no increased effect seen when the two exposures were combined [23]. A study of Canadian welders, carried out at around the same 


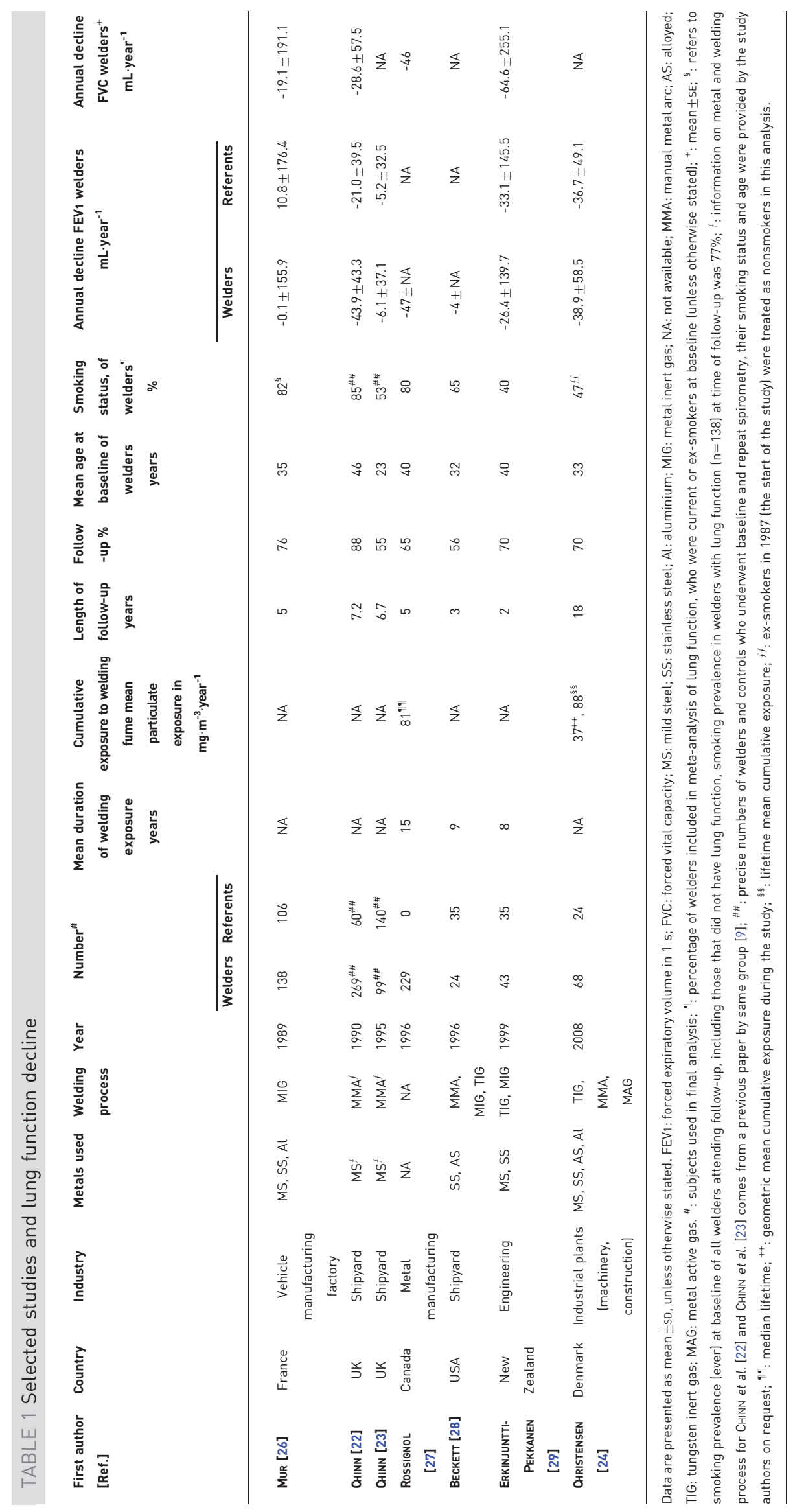


time as the more recent UK work, showed no significant decline in lung function after adjustment for smoking [27]. In a 5\% volunteer sample of welders at a US shipyard, lung function did not change significantly over 3 years of follow-up [28]. Neither of these studies included a referent group. In contrast, a study set in a New Zealand engineering company [29] suggested that welders who smoked or did not have access to local exhaust ventilation had an accelerated decline in FEV1. In this study, the difference in lung function decline between welders and nonwelders was not significant. The most recent selected publication, an 18-year follow-up of a mixed population of Danish welders [24], included exposure measurements. The authors concluded that at contemporary exposures, the average annual excess in functional decline among welders was unlikely to exceed $25 \mathrm{~mL}$ in smokers and $10 \mathrm{~mL}$ in nonsmokers.

\section{Exposure assessment}

Only two studies reported estimates or measures of particulate or fume exposure. Median cumulative lifetime exposure to welding fume was estimated to be $81 \mathrm{mg} \cdot \mathrm{m}^{-3} \cdot \mathrm{year}^{-1}$ in the study of Canadian welders, with estimated mean exposures to welding fume of $5-6 \mathrm{mg} \cdot \mathrm{m}^{-3}$ [27]; in this population, the decline in FEV1 among welders was $-47 \mathrm{~mL} \cdot \mathrm{year}^{-1}$. The estimated geometric mean cumulative lifetime exposure in the Danish study was $88 \mathrm{mg} \cdot \mathrm{m}^{-3}$ years and the cumulative exposure to welding fume during the study $37 \mathrm{mg} \cdot \mathrm{m}^{-3}$ years [24]; despite lower exposure levels in the Danish study $\left(1.3-3.5 \mathrm{mg} \cdot \mathrm{m}^{-3}\right)$, lung function decline was similar to the Canadian study, at $-40.6 \mathrm{~mL} \cdot$ year $^{-1}$.

Two papers referred to analyses based on type of metal welded $[24,26]$; in one, mild steel welders had an improvement in lung function over time, irrespective of smoking status, whereas stainless-steel welders who smoked had a small decline of $-2.6 \mathrm{~mL} \cdot$ year $^{-1}$, with nonsmokers showing an average improvement of $+8.4 \mathrm{~mL} \cdot$ year $^{-1}$ [26]. In the Danish study, no effects of metal or welding method on FEV1, FVC or FEV1/ FVC ratio were found [24].

\section{Meta-analysis: lung function decline}

Five studies included a referent population [22-24, 26, 29]. Using information from these we calculated a pooled estimate of the difference in annual FEV1 decline of $-9.0 \mathrm{~mL} \cdot \mathrm{year}^{-1}$ (95\% CI -22.5-4.5) between welders and referents; this difference was not statistically significant $(\mathrm{p}=0.193)$ (fig. 1$)$. There was no significant correlation between the proportion of workers followed up in these studies and the estimated rate of FEV1 decline between welders and referents (Pearson's $\rho=-0.76)(p=0.136)$.

The studies included in the meta-analysis also examined the effects of smoking and were used to generate pooled estimates stratified by smoking status. The WMD in annual FEV1 decline between welders and referents who smoked was $-13.7 \mathrm{~mL} \cdot$ year $^{-1}\left(95 \%\right.$ CI $-33.6-6.3 \mathrm{~mL} \cdot$ year $\left.^{-1} ; \mathrm{p}=0.179\right)$. For welders and referents who did not smoke the estimated difference was $-3.8 \mathrm{~mL} \cdot \mathrm{year}^{-1}$ (95\% CI -20.2-12.6 $\mathrm{mL} \cdot \mathrm{year}^{-1}$; $\mathrm{p}=0.650$ ). The forest plots for these studies are shown in figure 2 .

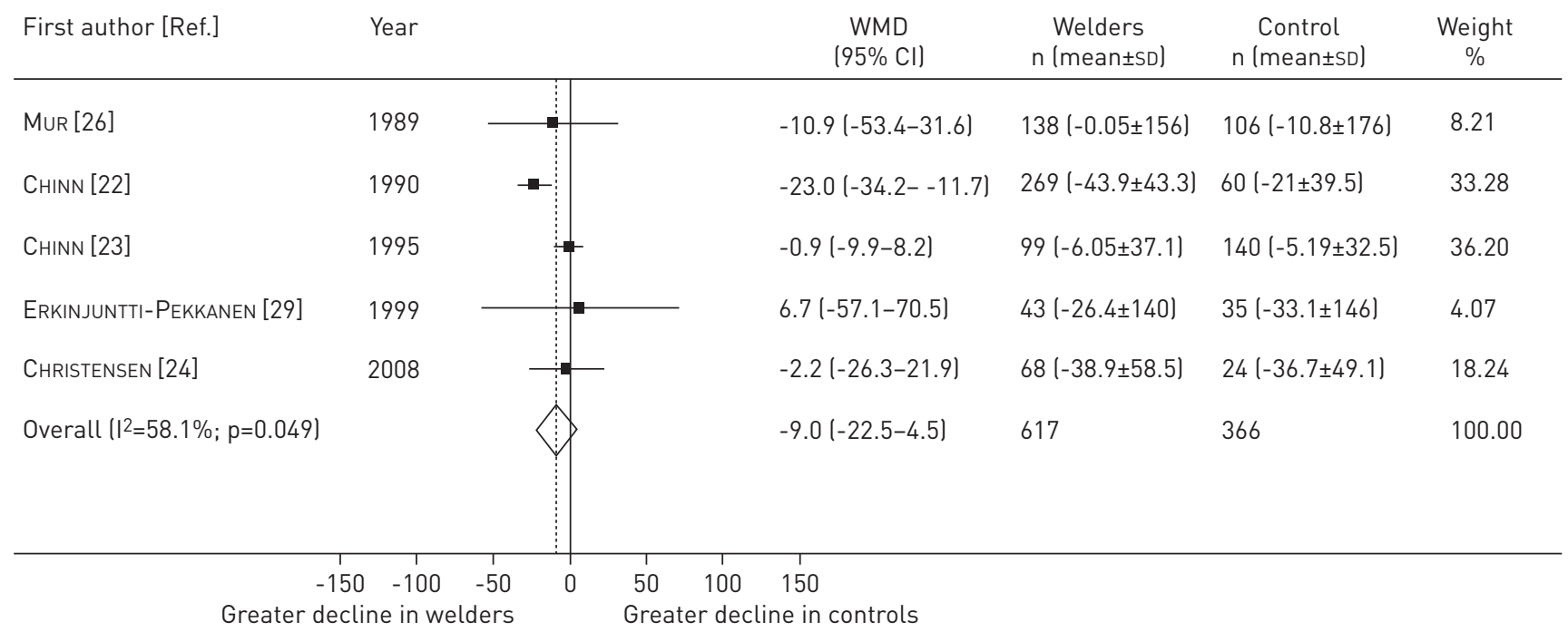

FIGURE 1 Forest plot of weighted mean difference (WMD) and 95\% confidence interval for estimates of annual decline in forced expiratory volume in $1 \mathrm{~s}$ (in

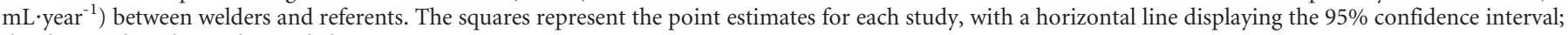
the diamonds indicate the pooled WMD. 


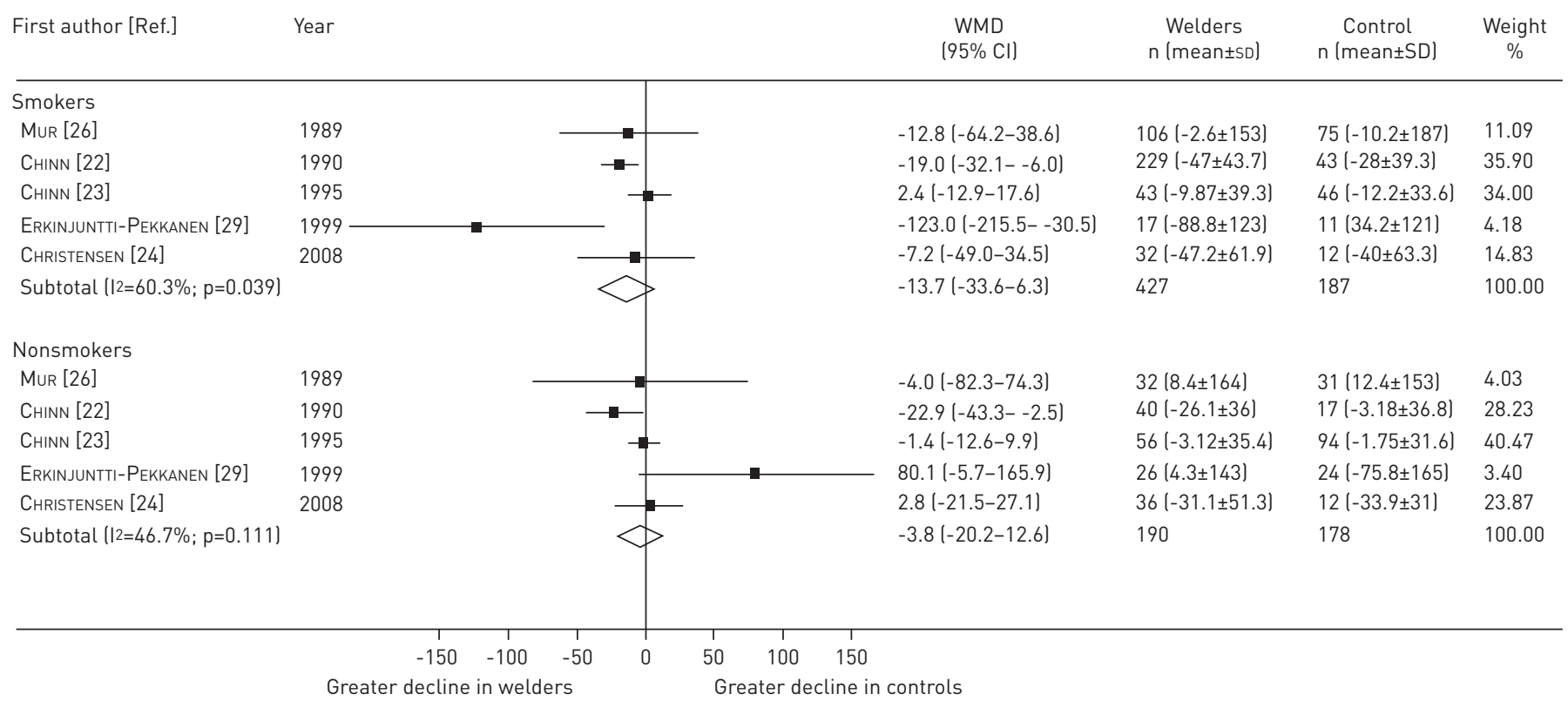

FIGURE 2 Forest plot of weighted mean difference (WMD) and 95\% confidence interval for estimates of annual decline of forced expiratory volume in $1 \mathrm{~s}$ (in $\mathrm{mL} \cdot$ year $\left.^{-1}\right)$ in welders who did and did not smoke and referents who did and did not smoke. The squares represent the point estimates for each study, with a horizontal line displaying the $95 \%$ confidence interval; the diamonds indicate the pooled WMD.

\section{Review of other lung function indices}

Numerical data for FVC changes were published in four papers [22, 26, 27, 29], three of which [22, 26, 29] provided information on variance in both welders and referents. In these, the pooled difference in FVC annual decline between welders and controls was $-22.0 \mathrm{~mL} \cdot \mathrm{year}^{-1}\left(95 \% \mathrm{CI}-37.4--6.6 \mathrm{~mL} \cdot \mathrm{year}^{-1} ; \mathrm{p}=0.005\right)$. By virtue of its size, one study [22] contributed $88 \%$ of the weighting in the meta-analysis of FVC annual decline (online supplementary appendix 2). The other three studies provided only a narrative commentary on FVC to the effect that welding had no significant effect on longitudinal change $[23,24,28]$, although in one, changes in FVC were described as "on average positive" [23].

Three studies reported changes in FEV1/FVC in welders [24, 26, 27]; two published their data, one showing an annual improvement in ratio of $0.3-0.5 \%$ that was not significantly different between welders and referents [26], and another an annual decline of $-0.3 \%$, which did not vary according to duration of exposure [27]. The third study reported no effect [24].

Small airway flow measurements were published in three of the seven papers [22, 26, 29], two using midexpiratory flow values at 50\% and 25\% of FVC (MEF50\% and MEF25\%, respectively). One quoted results for all subjects regardless of smoking, with annual declines in MEF50\% and MEF25\% of $-74 \mathrm{~mL}$ and $-26 \mathrm{~mL}$, respectively, in welders and $-40 \mathrm{~mL}$ and $-15 \mathrm{~mL}$, respectively, in referents [22]. In another study, data were stratified by smoking; MEF50\% fell by $-89 \mathrm{~mL} \cdot$ year $^{-1}$ in welders who smoked and $-74 \mathrm{~mL} \cdot$ year $^{-1}$ in welders who did not smoke with declines of $-65 \mathrm{~mL} \cdot$ year $^{-1}$ in smoking and $-55 \mathrm{~mL} \cdot$ year $^{-1}$ in nonsmoking referents. The estimated annual decline in MEF $25 \%$ was higher in welders and (marginally) in smokers: $-32 \mathrm{~mL} \cdot \mathrm{year}^{-1}$ and $-31 \mathrm{~mL} \cdot$ year $^{-1}$ in welders who smoked and welders who did not smoke, respectively, and $-18 \mathrm{~mL} \cdot$ year $^{-1}$ and $-14 \mathrm{~mL} \cdot$ year $^{-1}$ in nonwelders who smoked and did not smoke, respectively [26]. The third study reported an increase in forced expiratory flow at $25-75 \%$ of FVC $(\mathrm{FEF} 25-75 \%)$ of $78 \mathrm{~mL} \cdot$ year $^{-1}$ in welders and $161 \mathrm{~mL} \cdot$ year $^{-1}$ in referents [29]. Two further papers commented on small airway function without publishing data, one stating that welding had a detrimental effect independent of smoking [23], and the other contradicting this [28]. Due to the paucity of comparable data, meta-analysis of small airway measurements was not performed.

\section{Change in respiratory symptoms between initial and follow-up assessment of welder cohorts}

While all the selected studies described the collection of respiratory symptom information, publication of their findings was neither universal nor easily comparable. Two papers reported odds ratios for the development of respiratory symptoms during follow-up [22, 23]; in the first, there was an increased risk of incident dyspnoea related to welding (OR 2.8, 95\% CI 1.1-7.0) and of chronic bronchitis, increased by smoking (OR 2.0, 95\% CI 1.1-3.5) but unrelated to trade [22]. In the second, the development of a chronic productive cough was related to welding (OR 2.8, 95\% CI 1.2-6.4), with a slightly greater risk of other 
chronic symptoms (cough and wheeze) related to smoking but not to employment [23]. Three other studies compared the prevalence of symptoms at initial assessment and follow-up, one noting that symptom evolution "was not statistically different between welders and referents" [26], while the other two found a higher symptom prevalence in welders than referents at both time-points and, in both groups, a decline in prevalence during follow-up $[28,29]$. In two papers, the authors commented that smoking significantly increased the prevalence of symptoms $[22,26]$.

\section{Discussion}

This systematic review of the published literature on lung function decline and respiratory symptom development in welders highlights the difficulty in obtaining robust information to examine the association between welding and long latency respiratory disease. Our pooled estimates, derived from a systematic examination of published longitudinal studies, suggest that annual rates of FEV1 decline are greater in welders than in workplace referents and especially so in welders who smoke, although the differences are not statistically significant. Information on respiratory symptoms in the same studies was less easy to analyse but suggests that increasing symptoms over time are more strongly associated with smoking than with welding. These findings have important implications both for safety and for occupational health professionals who care for welders, at the very least, to support a strategy of targeted smoking cessation advice to individuals working in the trade.

We focussed our attention on FEV1 because it was the most widely available measure of lung function; in each case, it was measured without the use of a bronchodilator. A reduction in FEV1 is usually indicative of airway obstruction, reversible or otherwise, but may also reflect restrictive lung disease. An obstructive explanation is generally favoured [30] and welding fume contains several components that have been shown to be airway irritants in laboratory studies [3]. The information available from the studies we examined provided only limited support for small airways obstruction, although measurements of this are unreliable [31]. Asthma caused by welding fume has been described, but is probably rare [8], and in only one of the studies was bronchial responsiveness studied prospectively [28]. Using very high (10-fold) concentrations of methacholine, the authors found no relationship between bronchial hyperresponsiveness and lung function decline; additionally, the proportion of welders reacting to methacholine did not change significantly during follow-up. While the evidence is not conclusive, we suggest that the most plausible explanation for the changes in FEV1 that we report is one of airflow obstruction. We note, however, that the available findings for changes in FEV1/FVC ratio were inconsistent and the pooled estimate for decline in FVC in welders compared with referents, admittedly derived almost entirely from a single study, was slightly greater than that for FEV1 and was statistically significant. Thus the findings do not exclude the possibility of a restrictive pattern of disease. None of the seven studies reviewed took into account a history of metal fume fever or pneumonia.

Smoking was very prevalent in all the studies we examined, and in the five where its effects were examined separately, four reported a decline (significant in three) in welders who smoked that was over and above any effect of welding [22-24, 29]. In the fifth study [26], no significant change was found in relation to either smoking or welding. Our meta-analyses, when stratified by smoking, demonstrated small differences, but these did not reach statistical significance. A larger pooled estimate of excess decline between welders who smoked and their smoking controls was observed than the estimate between nonsmoking subject groups; however, the confidence intervals for the pooled estimates overlap. These findings suggest that the adverse effects of welding fume may be confined to those welders who smoke, reflecting perhaps additive effects of two concurrent sources of airway irritation or, alternatively, a chemical synergy. Other factors may, however, confound this relationship; smokers, for example, may adopt a more haphazard approach to respiratory protective equipment.

Our pooled estimates of annual decline in lung function were smaller than many might have anticipated. The explanations for this are complex, but they will include the well-known difficulties of longitudinal spirometry [32], bias arising from the design and/or conduct of some studies and the relative fitness and youth of the workforces studied. Rossignol et al. [27] commented on the possibility of a training effect, which would underestimate any true decline, a phenomenon noted elsewhere [33, 34]. These small differences in decline between welders and referents are not in themselves clinically significant. Importantly, the lack of statistical significance between groups may be due to small sample size leading to a lack of statistical power. Two of the five studies used to generate pooled estimates $[23,24]$ included employees who were still young enough (aged $<20$ years) not to have reached maximal lung function, and thereby probably underestimated any effect of welding on FEV1 decline. However, in one of these studies [24], the welders were on average older than the referent population, possibly leading to an overestimate of effect. Reassurance that age is not wholly responsible derives from this study [24], with the longest duration of follow-up, in which baseline age was not significantly associated with lung function decline. 
We elected to examine only longitudinal studies, which, if they cover a sufficient period [27, 35], are more likely to produce a valid measure of an occupational exposure effect [27]. However, few studies were identified as suitable; most had short follow-up times and there was significant between-study heterogeneity. In addition, only two sequential measurements of spirometry were available in four of the five studies in the meta-analysis; interestingly, in the fifth, where four annual measurements were made [26], there was no evidence of a decline in FEV1. As well as the obvious limitations of conducting metaanalysis of a small number of studies, we did not have sufficient information to explore in detail the potential reasons for this variation, but have considered a number of possible explanations. First, the selection process of the cohorts was probably variable; in one [26], the authors commented that at initial cross-sectional analysis, welders with longer exposures had better lung function, suggesting a "healthy selection" effect. Secondly, retention rates varied between $45 \%$ and $88 \%$ and, although the association between follow-up rates and magnitude of decline was not significant, a healthy survivor effect cannot be excluded. In some studies, retention was differential and related to exposure [23, 24, 26, 28, 29], and, in all cases, to smoking status [22-24, 26, 29]. Thirdly, two studies explicitly excluded employees with asthma [23, 28]. Collectively, these differences probably explained much of the heterogeneity and might imply that our findings underestimate the true effect of welding exposures.

Few studies reported detailed measurements of exposure, but the most recent, including an exposure matrix derived from occupational histories and validated with air sampling [24], failed to find a relationship between cumulative welding particulate exposure (range $0-42 \mathrm{mg} \cdot \mathrm{m}^{-3} \cdot \mathrm{year}^{-1}$ ) and $\mathrm{FEV} 1$ decline. ERKINJUNTTI-PEKKANEN et al. [29] reported that welders without personal or environmental protection had a significantly steeper decline in lung function, especially if they were smokers; indeed there was no evidence of a significant decline in nonsmoking protected welders. Similarly, in a study of British welders [23], the constant use of local ventilation was associated with a smaller decline in lung function. Otherwise, and unfortunately, the studies we examined included males working in a variety of industries, using different welding methods and means of respiratory protection. These differences make it essentially impossible collectively to identify which components of welding fume or which welding practices are potentially hazardous and how such hazards may specifically be avoided.

The findings of this systematic review suggest that welding may be associated with an accelerated decline in lung function, particularly in combination with smoking. They support a role for effective control of welding fume using local exhaust ventilation, targeted support for smoking cessation and vigilant, longitudinal and high-quality respiratory surveillance. There remain considerable uncertainties over the magnitude and determinants of risk in this important occupational group.

\section{Acknowledgements}

We are very grateful to Sheila Thomas, Linda Dumper and Lorna Laken (TWI, Cambridge, UK) and Magda Wheatley (Department of Occupational and Environmental Medicine, Imperial College (NHLI), London, UK) for their help with the literature searches.

\section{References}

1 US Department of Labor Bureau of Labor Statistics. Occupational outlook handbook 2010-11. Washington DC, Superintendent of Documents, US Government Printing Office, 2010.

2 Ahsan SA, Lackovic M, Katner A, et al. Metal fume fever: a review of the literature and cases reported to the Louisiana Poison Control Center. J La State Med Soc 2009; 161: 348-351.

3 Antonini JM, Taylor MD, Zimmer AT, et al. Pulmonary responses to welding fumes: role of metal constituents. $J$ Toxicol Environ Health A 2004; 67: 233-249.

4 Palmer KT, Poole J, Ayres JG, et al. Exposure to metal fume and infectious pneumonia. Am J Epidemiol 2003; 157: 227-233.

5 Ambroise D, Wild P, Moulin JJ. Update of a meta-analysis on lung cancer and welding. Scand J Work Environ Health 2006; 32: 22-31.

6 Sørensen AR, Thulstrup AM, Hansen J, et al. Risk of lung cancer according to mild steel and stainless steel welding. Scand J Work Environ Health 2007; 33: 379-386.

7 El-Zein M, Malo JL, Infante-Rivard C, et al. Incidence of probable occupational asthma and changes in airway calibre and responsiveness in apprentice welders. Eur Respir J 2003; 22: 513-518.

8 Lillienberg L, Zock JP, Kromhout H, et al. A population-based study on welding exposures at work and respiratory symptoms. Ann Occup Hyg 2008; 52: 107-115.

9 Cotes JE, Feinmann EL, Male VJ, et al. Respiratory symptoms and impairment in shipyard welders and caulker/ burners. Br J Ind Med 1989; 46: 292-301.

10 Luo JC, Hsu KH, Shen WS. Pulmonary function abnormalities and airway irritation symptoms of metal fumes exposure on automobile spot welders. Am J Ind Med 2006; 49: 407-416.

11 Ozdemir O, Numanoğlu N, Gönüllü U, et al. Chronic effects of welding exposure on pulmonary function tests and respiratory symptoms. Occup Environ Med 1995; 52: 800-803.

12 Bradshaw LM, Fishwick D, Slater T, et al. Chronic bronchitis, work related respiratory symptoms, and pulmonary function in welders in New Zealand. Occup Environ Med 1998; 55: 150-154. 
13 Hayden SP, Pincock AC, Hayden J, et al. Respiratory symptoms and pulmonary function of welders in the engineering industry. Thorax 1984; 39: 442-447.

14 Fogh A, Frost J, Georg J. Respiratory symptoms and pulmonary function in welders. Ann Occup Hyg 1969; 12: 213-218.

15 Meo SA, Azeem MA, Subhan MM. Lung function in Pakistani welding workers. J Occup Environ Med 2003; 45: 1068-1073.

16 Hunnicutt TN Jr, Cracovaner DJ, Myles JT. Spirometric measurements in welders. Arch Environ Health 1964; 8: 661-669.

17 Sobaszek A, Edme JL, Boulenguez C, et al. Respiratory symptoms and pulmonary function among stainless steel welders. J Occup Environ Med 1998; 40: 223-229.

18 Oxhoj H, Bake B, Wedel H, et al. Effects of electric arc welding on ventilatory lung function. Arch Environ Health 1979; 34: 211-217.

19 Sjögren B, Ulfvarson U. Respiratory symptoms and pulmonary function among welders working with aluminum, stainless steel and railroad tracks. Scand J Work Environ Health 1985; 11: 27-32.

20 Wells GA, Shea B, O'Connell D, et al. The Newcastle-Ottawa Scale (NOS) for assessing the quality of nonrandomised studies in meta-analyses. www.ohri.ca/programs/clinical_epidemiology/oxford.htm Date last accessed: May 8, 2013.

21 Stroup DF, Berlin JA, Morton SC, et al. Meta-analysis of observational studies in epidemiology: a proposal for reporting. Meta-analysis Of Observational Studies in Epidemiology (MOOSE) group. JAMA 2000; 283: 2008-2012.

22 Chinn DJ, Stevenson IC, Cotes JE. Longitudinal respiratory survey of shipyard workers: effects of trade and atopic status. Br J Ind Med 1990; 47: 83-90.

23 Chinn DJ, Cotes JE, el Gamal FM, et al. Respiratory health of young shipyard welders and other tradesmen studied cross sectionally and longitudinally. Occup Environ Med 1995; 52: 33-42.

24 Christensen SW, Bonde JP, Omland O. A prospective study of decline in lung function in relation to welding emissions. J Occup Med Toxicol 2008; 3: 6.

25 Deeks JJ, Higgins JPT, Altman DG, et al. Chapter 9: analysing data and undertaking meta-analyses. In: Higgins JPT, Green S (eds). Cochrane Handbook for Systematic Reviews of Interventions Version 5.1.0. London, The Cochrane Collaboration. Available from http://handbook.cochrane.org/ Date last accessed: May 8, 2013. Date last updated: March 2011.

26 Mur JM, Pham QT, Teculescu D, et al. Arc welders' respiratory health evolution over five years. Int Arch Occup Environ Health 1989; 61: 321-327.

27 Rossignol M, Seguin P, DeGuire L. Evaluation of the utility of spirometry in a regional public health screening program for workers exposed to welding fumes. J Occup Environ Med 1996; 38: 1259-1263.

28 Beckett WS, Pace PE, Sferlazza SJ, et al. Airway reactivity in welders: a controlled prospective cohort study. J Occup Environ Med 1996; 38: 1229-1238.

29 Erkinjuntti-Pekkanen R, Slater T, Cheng S, et al. Two year follow up of pulmonary function values among welders in New Zealand. Occup Environ Med 1999; 56: 328-333.

30 Pride NB. Tests of forced expiration and inspiration. In: Hughes JMB, Pride NB, eds. Lung Function Tests: Physiological Principles and Clinical Applications. London, WB Saunders, 2003; pp. 3-26.

31 Green M, Mead J, Turner JM. Variability of maximum expiratory flow-volume curves. J Appl Physiol 1974; 37: 67-74.

32 Hnizdo E, Yu L, Freyder L, et al. The precision of longitudinal lung function measurements: monitoring and interpretation. Occup Environ Med 2005; 62: 695-701.

33 Burrows B, Lebowitz MD, Camilli AE, et al. Longitudinal changes in forced expiratory volume in one second in adults. Methodologic considerations and findings in healthy nonsmokers. Am Rev Respir Dis 1986; 133: 974-980.

34 Rom WN, Wood SD, White GL, et al. Longitudinal evaluation of pulmonary function in copper smelter workers exposed to sulfur dioxide. Am Rev Respir Dis 1986; 133: 830-833.

35 Louis TA, Robins J, Dockery DW, et al. Explaining discrepancies between longitudinal and cross-sectional models. J Chronic Dis 1986; 39: 831-839. 